\title{
NÚCLEO DE DIREITOS HUMANOS - UFOP E PLANO NACIONAL DE EDUCAÇÃO: EXPERIÊNCIA DA EXTENSÃO UNIVERSITÁRIA COM OS SUJEIT( )S DISSIDENTES
}

\author{
Nucleus Human Rights core and the National Education Plan: the experience of university \\ extension with dissident subjects
}

Autores

Rainer Bomfim. Mestrando em Direito pela Universidade Federal de Ouro Preto (UFOP). Membro do Grupo de Estudos “Omissão Legislativa e o papel do Supremo Tribunal de Justiça: estudo sobre a Ado n. 26".

E-mail: rainerbomfim@outlook.com

Jessica de Paula Bueno da Silva. Mestra em Direito no Programa "Novos Direitos, Novos Sujeitos" do PPGD - UFOP. Bolsista UFOP. Membro do Grupo de Estudos "Omissão Legislativa e o papel do Supremo Tribunal de Justiça: estudo sobre a Ado n. 26". E-mail: jessicadepaulabueno@gmail.com

Alexandre Gustavo Melo Franco Bahia. Doutor pela UFMG. Professor Adjunto na UFOP e IBMEC-BH.

E-mail: alexandre@ufop.edu.br

Recebido em: 17/04/2019 Aprovado em: 01/08/2019

DOl: 10.12957/interag.2019.41999

\section{Artigo}

\section{Resumo}

Trata-se sobre como a extensão universitária desenvolvida pelo Núcleo de Direitos Humanos se relaciona com os sujeitos dissidentes e com as diretrizes do Plano Nacional de Educação. Utiliza-se da vertente metodológica jurídico-sociológica. Para isso constrói-se o estudo apresentando uma breve narrativa da história do NDH-UFOP para mostrar a mudança temática do programa após a aprovação do Plano Nacional de Educação, o qual é demonstrado em seguida

\section{Abstract}

It is about how the university extension developed by the Nucleus of Human Rights relates to the dissident subjects and with the directives of the National Plan of Education. The juridical-sociological methodological aspect is used. To this end, the study is based on a brief narrative of history the NDH-UFOP to show the thematic change of the program after the approval of the National Education Plan, which is shown below in the points dealing with extension. Afterwards, dis- 
nos pontos que tratam sobre extensão. Após, conceitua-se sujeit( )s dissidentes e apresentam os projetos que se relaciona com tal conceituação.

Palavras- chave: Extensão Universitária, Plano Nacional de Educação, Sujeitos dissidentes.

Área Temática: Direitos Humanos e Justiça

Linha Temática: Direitos Humanos sident subjects are conceptualized and present the projects that are related to such conceptualization.

Keywords: University Extension, National Education Plan, Dissident Subjects.

\section{Introdução}

O programa de extensão, que é um termo guarda-chuva utilizado um conjunto de projetos de extensão que se desenvolvem sob a mesma temática, em que se tem como panorama central da análise é o Núcleo de Direitos Humanos da UFOP (NDH) é vinculado ao Departamento de Direito da UFOP e foi criado em 2007. Ele é composto por vários projetos que objetivam a promoção prática, a partir de conhecimentos teóricos, de uma cultura de Direitos Humanos na cidade de Ouro Preto e região, com o desenvolvimento da experiência da extensão universitária há 11 anos. No ano de 2018, o referido programa conta com 8 (oito) projetos, 7 (sete) professores orientadores e 35 (trinta e cinco) alun( )s extensionistas participando das execuções de suas atividades e envolvendo centenas de pessoas da cidade/região em que se situa a Universidade Federal de Ouro Preto. Vale lembrar que com o novo Plano Nacional de Educação, aprovado em 2014, pelo menos $10 \%$ (dez por cento) do total de créditos curriculares exigidos para a graduação devem ser preenchidos em programas e projetos de extensão universitária.

O estudo apresenta-se sob a vertente metodológica jurídico-sociológica, no sentido elaborado por Miracy Gustin e Maria Teresa Fonseca Dias. Para tanto será utilizado o raciocínio indutivo, pois a partir de dados localizados pretende-se elaborar um panorama da realidade ouro-pretana a partir das experiências e pesquisas realizadas pelos projetos de extensão com focos $\mathrm{n}$ ( )s sujeit( )s dissidentes.'

Utiliza-se do marcador "( )" como forma de fugir dos binarismos consolidados na história do ocidente que se expressão muitas vezes na linguagem, entendendo também que existem pessoas que não se enquadram no padrão a/o por isso não se reproduz nas duas formas. Soma-se a isso a utilização de tal marcador para representar um espaço de vazio e para se mostrar que não precisa expressar com o masculino ou feminino, que não somos compostos apenas por tais gêneros. O vazio é considerado um espaço de luta, por isso o esforço desse texto em construir uma linguagem que se expressa no campo vazio.

As atividades desenvolvem-se sob a metodologia da pesquisa-ação desenvolvida por Michel Thiollent que se caracteriza pela pesquisa social em estreita associação com uma ação ou com a resolução de um problema coletivo e no qual os pesquisadores e os participantes representativos da realidade a ser investigada estão envolvidos de modo cooperativo e participativo, sendo que tod( )s participam ativamente do processo de 
construção do produto social. ${ }^{2}$

O programa busca consolidar a cidadania e a promoção de Direitos na esfera da comunidade ouropretana e região e ocorre através das ações realizadas nos Projetos, como: orientações jurídicas à população mais carente; consolidação de direitos nos distritos afastados de Ouro Preto; ida às escolas secundaristas para fins de formação sobre o funcionamento do processo político/legislativo através do parlamento jovem; realização de cursos sobre Direitos Humanos e Direitos Fundamentais; promoção dos direitos da criança e do adolescente e, também, dos direitos da pessoa com deficiência; realização de eventos de conscientização de direitos à comunidade e outros ${ }^{3}$. Ao mesmo tempo, pretende-se desenvolver conhecimentos para ( )s alun( )s participantes e para a comunidade envolvida acerca de uma cultura de Direitos Humanos que possa ser replicada pelos envolvidos para além do $\mathrm{NDH}$.

A partir do ano de 2016, o programa direciona parte de suas atividades para o trabalho dos Direitos Humanos voltados ao reconhecimento de sujeit( )s dissidentes ao Direito Moderno, sendo estes entendimentos como sujeit( )s que até então não tinham seus direitos reconhecidos pelo ordenamento jurídico posto. Então, tendo em vista esse novo enfoque, que tem relação direta com as pesquisas desenvolvidas no Departamento de Direito (Graduação e Mestrado) da UFOP, foram iniciados projetos relacionados a pessoas com deficiência, a mulheres e à população LGBTI, para, a partir da metodologia do programa, realizar construções nos seus micros espaços que possibilitem a inclusão dessa população e o mapeamento dos dados relacionados a esses sujeitos de pesquisa.

Dessa forma, apresentam-se os projetos de extensão desenvolvidos pelo Núcleo de Direitos Humanos-UFOP, com destaque àqueles em que se trabalha na prática ( )s sujeit( )s dissidentes com os paralelos da pesquisa e da extensão desenvolvidos na Universidade Federal de Ouro Preto.

O texto encontra-se dividido em uma breve reconstrução da história do NDH; após isso tem-se a exposição da metodologia utilizada pelo programa desde sua criação, depois a discussão sobre a mudança no Plano Nacional da Educação seguido da conceituação de sujeit( )s dissidentes, logo após é feita a descrição dos projetos que trabalham com o conceito acima relacionado e, por fim, considerações finais sobre o programa e trabalhos sobre os sujeito( )s dissidentes.

\section{Breve narrativa histórica do Núcleo de Direitos Humanos - UFOP}

O Programa é vinculado à Pró-reitoria de Extensão. Esse programa surgiu em 2007 como um projeto de extensão para ampliar as atividades desenvolvidas pelo Departamento de Direito da própria Universidade. Como foi trazido por Rainer Bomfim e Alexandre Bahia (2018) em outra oportunidade:

A criação do projeto foi motivada pela existência do projeto "Reconhecer UFOP", uma vertente do programa "Reconhecer" da Secretaria de Educação Superior do Ministério da Educação, que em 2006, tinha como objetivo principal identificar as necessidades e as demandas da população carcerária. Com o propósito de ampliar essa vivência surgiu a proposta de criação do Núcleo de Direitos Humanos em 2007.

O NDH-UFOP, desde sua criação, pauta-se no diálogo com a comunidade, em que os sujeitos sociais e os extensionistas são atores de modificação da realidade encontrada. Essa análise só se torna possível pela receptividade da comunidade e, também, das parcerias locais firmadas ao longo da história do projeto. ${ }^{4}$ 
Nos anos de 2008 a 2015 o NDH passou por renovações formais e estruturais, uma vez que, na análise de professores e extensionistas, alguns dos projetos já teriam cumprido o seu propósito perante a comunidade ouro-pretana e julgou-se necessário criar outros. Assim, o programa manteve-se com alguns dos seus projetos tradicionais, como o Parlamento Jovem e a Assessoria Jurídica Comunitária e foram criados outros, como o projeto Antônio Pereira, que surgiu através das demandas apresentadas pela população e pel( )s alun( )s, abrangendo, desde o início, uma série de ações conjuntas para atuar naquele distrito de Ouro Preto.

Nos anos seguintes, o NDH continua sua expansão trazendo questões ligadas à Diversidade e ao Reconhecimento de Direitos às minorias nos seus projetos de extensão e percebe-se a necessidade de transformar o NDH em um ambiente institucionalizado para a captação e recepção de demandas sociais e que podem ser conflituosas entre a comunidade ouro-pretana para escutar aqueles que são considerados como dissidentes ou que faltam à concretização de alguns dos seus direitos básicos serem assistidos. Assim, criam-se projetos especializadas como meios de comunicação direto com os setores que são marginalizados e historicamente oprimidos, seja pelas relações de trabaIho, por não Ihes atribuir capacidade, por relações hierárquicas e excludentes de gênero, orientação sexual ou por questões de cor. Com isso se pretende estudar e construir um canal a partir do qual as vozes daqueles que são silenciad( )s e vilipendiad( )s em seus direitos possam encontrar não apenas quem ( )s "escute", mas também que possa lhes dar aconselhamento e encaminhamento jurídicos.

\section{Metodologia do NDH}

A metodologia adotada pelo NDH tem sido a "pesquisa-ação", tal como descrita é por Michel Thiollent, que propõe que ( )s extensionistas e os atores comunitários são agentes ativos para alcançar um resultado positivo e reconhecido por ambos. Como é ilustrado no trecho:

A pesquisa-ação é um tipo de pesquisa social que é concebida e realizada em estreita associação com uma ação ou com a resolução de um problema coletivo e no qual os pesquisadores e os participantes representativos da situação da realidade a ser investigada estão envolvidos de modo cooperativo e participativo. ${ }^{5}$

A metodologia é utilizada desde o momento de captação de demandas do programa, visto que essas partem da própria comunidade e são institucionalizadas pelos professores por meio de seus projetos. A construção desse conhecimento parte de um viés plural em que se busca permitir o contato entre pessoas totalmente diferentes, com classes e formações acadêmicas totalmente distintas que é viabilizado a partir de uma ação daquele projeto que está inserido na maneira em que compartilham os conhecimentos (no termo mais amplo do termo) em prol de uma finalidade e constroem um produto juntos. Tal concepção de produto não se limita ao produto final da extensão, mas o produto dessa metodologia pode ser a modificação daquela realidade na qual eles estavam inseridos ou simplesmente a construção de novos conhecimentos que as partes não detinham a priori. 


\section{Mudança no Plano Nacional de Educação: advento da Lei 13.005/14 e a inserção da extensão como componente curricular}

Em 2014 foi sancionada a Lei n. 13.005/2014 que aprova um novo Plano Nacional de Educação (PNE) com vigência de 10 (dez) anos. Tal norma tem como diretrizes a promoção humanística, científica, cultural e tecnológica do País, promoção dos princípios do respeito aos direitos humanos, à diversidade e à sustentabilidade socioambiental, bem como a melhoria da qualidade da educação (art. $2^{\circ}$, IV, VI e VII da Lei 13.005/2014). ${ }^{6}$

Para que isso ocorra foram criadas estratégias como, por exemplo, "assegurar, no mínimo, 10\% (dez por cento) do total de créditos curriculares exigidos para a graduação em programas e projetos de extensão universitária, orientando sua ação, prioritariamente, para áreas de grande pertinência social" (meta 12, ponto 12.7 do anexo da Lei 13.005/2014).

Assim, as ações de extensão universitária ganham maior destaque na formação acadêmica e social dos cursos das Universidades. Muito embora o curso de Direito da UFOP ainda não tenha adotado tal normativa do percentual mínimo dos créditos da extensão dentro da sua grade curricular, ( )s alun( )s do curso de Direito da UFOP possuem interesse em tais ações, tendo em vista a existência de três grandes programas de extensão (Núcleo de Direitos Humanos, Direito e Sociedade e Núcleo de Assistência Jurídica e Laboratório Jurídico) com um total de vinte e um projetos de extensão dentro daqueles programas, conforme consta no site institucional da UFOP (www.proex.ufop. br). A inclusão da "creditação", como vem sendo chamada, está prevista na revisão do Projeto Pedagógico do Curso que vem sendo implementada.

Por um recorte metodológico, trata-se especificamente do NDH com suas ações, de tal maneira que as ações realizadas nos projetos encontram ligação com as linhas de pesquisa dos professores, o que proporciona a inter-relação necessária no Ensino, Pesquisa e Extensão.

Ademais, o NDH-UFOP ainda se articula por sua metodologia própria que foi acima apresentada, com a pesquisa que é desenvolvida no Departamento de Direito da UFOP, notadamente quanto ao Diretório de Pesquisa do CNPq "Núcleo de Estudos Constituição, Reconhecimento e Diversidade" e no Programa de Mestrado em Direito "Novos Direitos, Novos Sujeitos" da UFOP. Dessa forma, ampliam-se as atividades que já eram desenvolvidas pelo programa de Extensão desde sua criação no Programa de Mestrado que também adota a metodologia da Pesquisa-ação como base para a investigação social.

\section{Sujeit( )s dissidentes: conceituação e a aproximação com a teoria de Michel Foucault}

A sociedade moderna ocidental estabeleceu um padrão de sujeito: homem, branco, cristão, heterossexual, burguês, produtivo(produtivista) e isso é feito a partir de normalidades, de linearidades, comportamentos que criam "caixas" dentro das quais pessoas e identidades deveriam caber ${ }^{7}$. Há uma normalização compulsória centrada em binarismo, na homogeneização e otimização dos indivíduos para a construção da sociedade na qual se exerce um poder disciplinar para o controle e gestão (adestramento social) sobre os corpos em todos os seus aspectos a partir de conhecimentos especializados e institucionalizados. ${ }^{8}$

A especialidade dos conhecimentos se dava pelos meios médicos, jurídicos, acadêmi- 
cos, entre outros, que de alguma forma estabelecia a normalidade $d($ )s sujeit( )s e, logo, quem era excluído daquela sociedade. Tal normalidade era estabelecida através de binarismos (normal/anormal), como doente/não doente, louc( )/saudável, e aquel( )s que eram postos do lado negativo do conceito deveriam ser excluídos ou reabilitados. ${ }^{9}$ Por sua vez a institucionalização era feita pelo aparato estatal e social que verificava tais comportamentos como violentos, desumanizadores, mas se portavam da mesma forma pela normalização de tais condutas, visto que aquelas práticas se justificavam por se tratar de sujeit( )s dissidentes daquela norma, identidade, comportamento e/ou padrão imposto.

Diante desse cenário descrito, ( )s sujeit( )s dissidentes são aqueles que no contexto atual não estão no padrão hegemônico estabelecido, mas não estão necessariamente excluíd( )s, expuls( )s do convívio social e/ou têm seus comportamentos criminalizados. De tal forma que mulheres, negros, LGBTI podem ser tratados como sujeitos dissidentes, dado esse contexto de não adequação ao padrão conceituado.

\section{Projetos Desenvolvidos pelo Núcleo de Direitos Humanos - UFOP}

Os projetos que fazem parte do Programa NDH-UFOP dentro daquela reformulação referida a partir de 2015 são: Assessoria Jurídica Comunitária, Cartografia de Judicialização do desastre de Fundão, Diálogos Institucionais: debatendo os resultados do monitoramento da jurisprudência internacional pelo Observatório das Relações Internacionais, Direito da Pessoa com Deficiência, Formação cidadã: educação, direitos humanos e diversidade cultural, Ouvidoria Feminina: Athenas, Ouvidoria Insegurança do Trabalho, Ouvidoria LGBTI, Núcleo de Estudo em Diversidade, Gênero e Sociedade e Parlamento Jovem.

Para o presente e considerando o conceito de sujeit( )s dissidentes acima estabelecidos acima, serão trabalhados apenas aqueles que foram pensados dentro de tal lógica. Assim, estabelecida e discutida a pesquisa no DEDIR/Mestrado em Direito da UFOP sobre situações de exclusão, violência, marginalidade e discriminação - não apenas por um estudo teórico, mas também por demandas da comunidade (universitária e de fora da UFOP) que atestam aquelas situações - o NDH absorve as demandas daí resultantes e cria novos projetos.

\subsection{Direitos da Pessoa com Deficiência (DPD)}

O projeto nasce com a entrada em vigor do Estatuto da Pessoa com Deficiência (Lei no 13.146, de 6 de julho de 2015) no início de 2016. Essa lei traz complexas mudanças no tratamento jurídico da Pessoa com Deficiência, sendo que o conceito é trazido pela própria lei no seu art $2^{\circ}$. Como se vislumbra o texto legal:

"Art. $2^{\circ}$. Considera-se pessoa com deficiência aquela que tem impedimento de longo prazo de natureza física, mental, intelectual ou sensorial, o qual, em interação com uma ou mais barreiras, pode obstruir sua participação plena e efetiva na sociedade em igualdade de condições com as demais pessoas." ${ }^{10}$

Sobre esse dispositivo a autora lara Antunes de Souza traz a seguinte análise:

"O Estatuto traz conceito de deficiência que abrange várias de suas espécies, como a deficiência física, mental, intelectual ou sensorial. (...) O Estatuto da Pessoa com Deficiência adota conceitos de deficiência mental e intelectual que se concretizam quando retira da pessoa a possibilidade de participar das atividades cotidianas na sociedade em igualdade com outras pessoas sem aquela deficiência." 11 
Assim, por se tratar de uma inovação legislativa na seara das pessoas com deficiência, o NDH atento com essa nova demanda, cria o projeto com o intuito de levar a comunidade ouro-pretana e universitária a estudar e refletir sobre esse novo instrumento jurídico que promove a proteção dos direitos das pessoas com deficiência. Trata-se de uma forma para informar a comunidade sobre esses direitos buscando com que estes sejam respeitados, garantindo a inclusão.

\subsection{Núcleo de Estudos em Diversidade, Gênero e Sociedade (NEDGS-CHICA)}

O projeto foi criado em 2015 com o viés de discussão e argumentação para capacitar ( )s extensionistas sobre o tema a ser discutido e outro de ações concretas para promoção da comunicação da UFOP e da comunidade de Ouro Preto sobre questões de grupos minoritários historicamente excluídos pela sociedade brasileira em geral de tal forma a desmitificar as experiências de preconceito e discriminação existentes na sociedade. ${ }^{12}$

O grupo desenvolve também o projeto em três vertentes de trabalho, que são divididas para a promoção do maior diálogo entre a UFOP, a comunidade de Ouro Preto e setores externos. Essa subdivisão acontece da seguinte forma: o primeiro visa ampliar o debate sobre as motivações que levam à exclusão de grupos minoritários na Universidade e na comunidade ouro-pretana; o segundo objetiva levar as informações, bem como dar o direito a voz e reconhecimento daqueles que têm sido alvo destas exclusões discriminatórias; o terceiro possibilita a integração de grupos minoritários com a comunidade ouro-pretana.

\subsection{Educação, Direitos Humanos e Diversidade Cultural}

O projeto, que se iniciou em 2016, tem como base o processo educacional contemporâneo e tem por objetivo a formação cidadã d( )s jovens permitindo o desenvolvimento de reflexões a partir do contexto social no qual estão inseridos.

Dentro da realidade democrática do Estado brasileiro tona-se necessário que o tema dos Direitos Humanos entre na pauta educacional de forma consistente. Questões sobre o gênero, liberdade de expressão, responsabilidade social, meio ambiente natural e cultural, patrimônio histórico-cultural, diversidade cultural, tolerância, diferenças individuais, reconhecimento, identidade constitucional, etc., relacionam-se diretamente com o conceito de Direitos Humanos compreendido, para efeitos do projeto, como aqueles direitos consignados como fundamentais na Constituição de 1988.

Desta forma, uma educação cidadã deve buscar despertar $\mathrm{n}($ ) $)$ jovens o interesse pelas questões que cercam as possibilidades de compreensão e desenvolvimento dos seus projetos de vida individuais e, ao mesmo tempo, desenvolver uma reflexão crítica sobre o contexto social no qual seu projeto de vida está inserido.

A temática do Projeto se torna ainda mais sensível num momento em que vários Municípios, Estados (e até no nível federal há discussões a respeito) estão implementando mudanças educacionais para proibir discussões políticas nas escolas ("escola sem partido") ou sobre questões de gênero ("escola sem ideologia de gênero") ou mesmo ajuizando ação contra as escolas por tratarem sobre questões relacionadas a diversidade.

\subsection{Modelo de Ouvidoria NDH: Ouvidoria LGBT, Ouvidoria Feminina - Athenas, Ouvidoria da Insegurança no Trabalho e da Identidade Negra}

A Ouvidoria NDH reúne as quatro ouvidorias que foram os projetos criados em 2017 a partir da observação de discentes e docentes visando atender as demandas trazidas até o NDH, em que se relatam a violência relacionada à população LGBTI, aos negros, às mulheres e a( )s trabalhadores dentro das unidades e dos departamentos da UFOP, bem como nas repúblicas federais e particulares 
e também nas cidades de Ouro Preto e de Mariana e à discriminação por cor e raça.

Tratar os quatro projetos dentro de um programa só se faz possível haja vista a temática de cada um deles ser totalmente independente; todos têm suas demandas enviadas a uma plataforma e nessa plataforma ( ) usuári( ) indicará qual é o motivo, violação ou inquietude que Ihe levou a buscar a Ouvidoria. Assim, para o público externo existirá apenas a Ouvidoria NDH, enquanto internamente se faz necessária a divisão dos projetos visto que é preciso capacitar os ouvidores para o manuseio da plataforma e para o atendimento de acordo com a temática relacionada.

O objetivo principal das Ouvidorias é a proteção e a assessoria jurídica dos direitos daqueles grupos em que se destinam os trabalhos. Os projetos abarcam as cidades de Ouro Preto e de Mariana. A execução dos projetos é destinada a: receber, examinar, relatar, dar sugestões, prestar atendimento jurídico. O atendimento é online e acontece em uma plataforma chamada de Sistema de Gerenciamento de Conteúdo, sendo que a plataforma pode ser acessada pelo link https://www.ouvidoria.ndh.ufop.br/. Com um viés secundário o projeto também abrange a confecção de um material - como cartilhas, folders, entre outros - com conteúdo informativo sobre os direitos das vítimas. Ainda, o projeto tem o caráter de formar uma base de dados sobre a ocorrência de incidentes de violência contra os setores analisados.

\section{Resultados Gerais}

O NDH revela-se um importante instrumento para a contribuição acadêmica $d($ )s alun( )s-extensionistas do curso de Direito da UFOP, pois estes estão em constante formação teórica - sendo que a todo instante devem se capacitar para tratar das questões vivenciadas - e práticas, uma vez que ( )s extensionistas são levados a lidar com questões de diversos setores da sociedade, o que contribui para uma formação multicultural, de conhecimentos, mas também de competências e habilidades, além de uma percepção plural da sociedade em que se é inserido, pois os diversos projetos tratam de questões atinentes à formação política e cultural de jovens a problemas relacionados à garantia de direitos daquela sociedade. Por fim, pontua-se que ( )s extensionistas são levados a uma percepção diferenciada da realidade sobre o mundo prático-jurídico do cotidiano do Direito, pois são capacitad( )s para uma compreensão mais atenta aos problemas sociais.

Como resultados gerais apresenta-se a capacitação d( )s extensionistas durante todo o processo de construção das atividades de extensão, de tal forma que cada projeto de forma individual produz resultados autônomos para a comunidade ouro-pretana, o que não se apresenta como objetivo de construção desse artigo.

Nesse sentido, o NDH tem 10 anos de história na construção de atividades de extensão com a comunidade, com a construção de uma realidade plural e democrática na cidade de Ouro Preto e, também, nos seus arredores, tendo em vista a existência de projetos que pretendem abarcar toda comunidade ufopiana (Ouro Preto, Mariana e João Monlevade).

\section{Considerações Finais}

Frente às ponderações trazidas, percebe-se que o NDH-UFOP é formado por projetos com diferentes áreas de atuação e públicos diversos e é preocupado com aqueles sujeit( )s dissidentes, seja para promoção de direitos ou para a assistência jurídica, tais medidas se realizam dentro de perspectivas teóricas e ações sociais. 
Ademais, atenta-se que a extensão universitária como forma e padrão de conhecimento e inter-relacionada com o ensino e pesquisa é uma realidade dentro do curso de Direito da UFOP, que tem ações sendo desenvolvidas pelo NDH desde 2007. Acrescenta-se que se faz necessária a inclusão da extensão dentro dos currículos nos moldes estabelecidos no PNE.

O Núcleo de Direitos Humanos, que tem parte de seus projetos relatados no presente artigo, nasceu com o objetivo de dar voz, informações e oportunidades para os sujeitos vulneráveis e invisíveis sociais envolvidos nesse grande processo de extensão. O programa já atendeu diversas faixas etárias e diferentes públicos-alvo, com as mais diversas atuações nos temas relacionados aos Direitos Humanos em busca de uma melhoria da situação daqueles envolvidos nos projetos. Nasce com o viés plural de permitir o contato entre pessoas totalmente diferentes, com classes sociais e com formações totalmente distintas. Sendo que uns/umas chegam como o conhecimento acadêmico e outr( )s com o conhecimento intitulado "de vida" para que juntos, sempre junt( )s, possamos construir algo melhor para aquela população em que estão (ou foram) inserid( )s. E no final, se é que existe este, saem transformad( )s, ou no mínimo diferentes, pois aquele que pensava no conhecimento acadêmico encontra um saber e uma realidade que não poderia ser traduzida por manuais, doutrinas, ou mesmo por professor( )s na sala de aula. Enquanto, aquele que detinha o conhecimento "de vida" sai com um sentimento de empoderamento, seja este em qual forma ocorra, com informações, atendimento jurídico, formação política, ou com a certeza que alguém está/esteve atento para aquela demanda e quer ajudar a transformar aquela população, ou quiçá, em uma pretensa afirmação, a sociedade. ${ }^{13}$

O Programa de Extensão "Núcleo de Direitos Humanos" complementa as ações já feitas no Departamento de Direito (graduação e pós-graduação) em reconhecer e efetivar os direitos fundamentais de sujeit( )s dissidentes, seja pelas ações concretas seja pela formação cidadã dada a( )s egress( )s.

\section{Contribuições dos Autores}

Rainer Bomfim é o autor principal da produção dessa obra.

Jessica de Paula Bueno da Silva é coautora da obra.

Alexandre Gustavo Melo Franco Bahia é o orientador dos trabalhos.

\section{Referências}

1.GUSTIN, Miracy Barbosa de Sousa; DIAS, Maria Tereza Fonseca. (Re) Pensando a Pesquisa Jurídica. 2a ed. Belo Horizonte: Del Rey, 2006.

2.THIOLLENT, Michel. Metodologia da pesquisa-ação. 18. ed. São Paulo: Cortez 2011.

3. BOMFIM, Rainer; BAHIA, Alexandre Gustavo Melo Franco. História do Programa $\mathrm{NDH}$ : (re)criação ao longo dos anos. In: BOMFIM, Rainer; BAHIA, Alexandre Gustavo Melo Franco; CAMILLOTO, Bruno(orgs). Universidade Pública e Direitos Humanos: a experiência em extensão da UFOP. Belo Horizonte: Conhecimento, 2018. P. 1-19

4. BOMFIM, Rainer; BAHIA, Alexandre Gustavo Melo Franco. História do Programa $\mathrm{NDH}$ : (re)criaçaõ ao longo dos anos. In: BOMFIM, Rainer; BAHIA, Alexandre Gustavo Melo Franco; CAMILLOTO, Bruno(orgs). Universidade Pública e Direitos Humanos: a experiência em extensão da UFOP. Belo Horizonte: Conhecimento, 2018. P. 6 
5. THIOLLENT, Michel. Metodologia da pesquisa-ação. 18. ed. São Paulo: Cortez 2011. P.13

6. BRASIL, Lei $n^{\circ} 13.005$ de 13 de junho de 2014. Plano Nacional de Educação.

7. BAHIA, Alexandre G. Melo Franco de Moraes. Sobre a (in)capacidade do direito de lidar com a gramática da diversidade de gênero. Revista Jurídica da Presidência, Brasília, v. 18, n. 116, Out. 2016./Jan. 2017. P. 481-506.

8. FOUCAULT, Michel. Microfísica do Poder. Rio de Janeiro: Edições Graal, 1979.p. 17

9. FOUCAULT, Michel. Microfísica do Poder. Rio de Janeiro: Edições Graal, 1979. P.91-101

10. BRASIL, Lei $n^{\circ} 13.146$ de 06 de julho de 2015. Estatuto da Pessoa com deficiência

11. SOUZA, lara Antunes de. Estatuto da Pessoa com Deficiência: Curatela e Saúde Mental. Belo Horizonte: DPlácido, 2016, p.269.

12. GARCIA, Luiz Carlos; FERREIRA, Paula Camila Veiga. Núcleo de Estudos em Diversidade, Gênero e Sociedade- NEDGS-CHICA. In: BOMFIM, Rainer; BAHIA, Alexandre Gustavo Melo Franco; CAMILLOTO, Bruno(orgs). Universidade Pública e Direitos Humanos: a experiência em extensão da UFOP. Belo Horizonte: Conhecimento, 2018. P. 161-172

13. BOMFIM, Rainer; Apresentação do livro. In: BOMFIM, Rainer; BAHIA, Alexandre Gustavo Melo Franco; CAMILLOTO, Bruno(orgs). Universidade Pública e Direitos Humanos: a experiência em extensão da UFOP. Belo Horizonte: Conhecimento, 2018. P. xiv 